09

\title{
Фоторефрактивная подстройка коэффициента деления интегрально-оптического направленного $X$-ответвителя на подложке ниобата лития
}

\author{
(C) М.В. Парфренов ${ }^{1,2}$, А.В. Тронев ${ }^{1,3}$, И.В. Ильичев ${ }^{1}$, П.М. Агрузов ${ }^{1}$, А.В. Шамрай ${ }^{1}$ \\ ${ }^{1}$ Физико-технический институт им. А.Ф. Иофрфе РАН, Санкт-Петербург, Россия \\ ${ }^{2}$ Санкт-Петербургский политехнический университет Петра Великого, Санкт-Петербург, Россия \\ ${ }^{3}$ Санкт-Петербургский национальный исследовательский университет информационных технологий, механики и оптики, \\ Санкт-Петербург, Россия \\ E-mail: mvparfenov@yandex.ru
}

Поступило в Редакцию 5 декабря 2018 г.

В окончательной редакции 5 декабря 2018 г.

Принято к публикации 6 декабря 2018г.

\begin{abstract}
Исследована возможность подстройки коэффициента деления мощности в интегрально-оптическом направленном ответвителе ( $X$-ответвителе) при возбуждении локального фоторефрактивного отклика в материале подложки $\left(\mathrm{LiNbO}_{3}\right)$. Проведено численное моделирование работы $X$-ответвителя, определены его участки, обладающие максимальной чувствительностью к фоторефракции. Получено соответствие расчетных данных и эксперимента. Максимальное изменение коэффициента деления в разветвителе составило величину порядка 1-2\%. Фоторефрактивная подстройка коэффициента использована для повышения контраста модулятора Маха-Цендера до уровня $47 \mathrm{~dB}$.
\end{abstract}

DOI: 10.21883/PJTF.2019.05.47386.17627

Ниобат лития $\left(\mathrm{LiNbO}_{3}\right)$ является одним из основных материалов интегральной оптики. Благодаря сильно выраженному электрооптическому эффекту Поккельса, а также хорошо отработанным технологиям изготовления в ниобате лития оптических волноводов с низкими потерями он широко применяется для производства оптических модуляторов $[1,2]$. В наиболее распространенной конфигурации такие модуляторы представляют собой интерферометры Маха-Цендера, в которых для деления мощности используются $X$-ответвители (направленные ответвители на основе связанных волноводов) или $Y$-разветвители (делители волнового фронта в волноводном исполнении). Из-за неточностей, имеющих место при изготовлении этих волноводных элементов (например, неточностей фотолитографии), у модуляторов на их основе есть разброс коэффициентов контраста в пределах 20-30 dB. Для многих практических задач этот разброс несуществен, но в ряде приложений требуются модуляторы с очень высоким коэффициентом контраста, например в некоторых видах оптических датчиков или системах квантовой криптографии $[3,4]$.

Увеличить точность изготовления интегральнооптических элементов затруднительно. В связи с этим вызывает интерес исследование механизмов подстройки коэффициента деления в уже изготовленных делителях мощности. Известно, что ниобат лития является фоторефрактивным материалом, у которого оптическое излучение высокой плотности мощности приводит к уменьшению показателя преломления в области засветки. В ниобате лития оно может достигать значений до $\Delta n_{p r} \sim 10^{-3}$ [5]. В то же время увеличение показателя преломления относительно показателя подложки у волноводов на подложке ниобата лития имеет те же значения по порядку величины $\left(\Delta n_{w g} \sim 10^{-3}\right)[6,7]$. Исходя из этого можно предполагать, что фоторефрактивная коррекция волноводных элементов на подложке ниобата лития возможна. Задача настоящей работы заключается в проверке этого предположения на примере подстройки коэффициента деления $X$-ответвителя, а также в разработке экспериментальных методов для ее реализации.

Было проведено численное моделирование с целью определить участки интегрально-оптического делителя мощности, чувствительные к фоторефрактивной коррекции. Была построена модель $X$-ответвителя (рис. $1, a$ ), конфигурация которого при идеальной точности изготовления должна обеспечивать деление оптической мощности в соотношении 50:50 на второй перекачке. С целью уменьшения вычислительной сложности была рассмотрена двумерная система с изотропным показателем преломления подложки, градиентные волноводы были заменены эквивалентными ступенчатыми волноводами с увеличением показателя преломления $\Delta n_{w g}=0.002$ и шириной $8 \mu \mathrm{m}$. Участок локального фоторефрактивного изменения показателя преломления был представлен прямоугольной областью размером $10 \times 10 \mu \mathrm{m}$ с равномерным уменьшением показателя преломления на $\Delta n_{p r}=-0.001$. Ввиду больших размеров интегрально-оптического элемента (много бо́льших оптической длины волны) численные расчеты выполнялись методом ВРМ (beam propagation method) в программном пакете OptiBPM. Анализ проводился для фундаментальной ТЕ-моды оптического волновода, ли- 


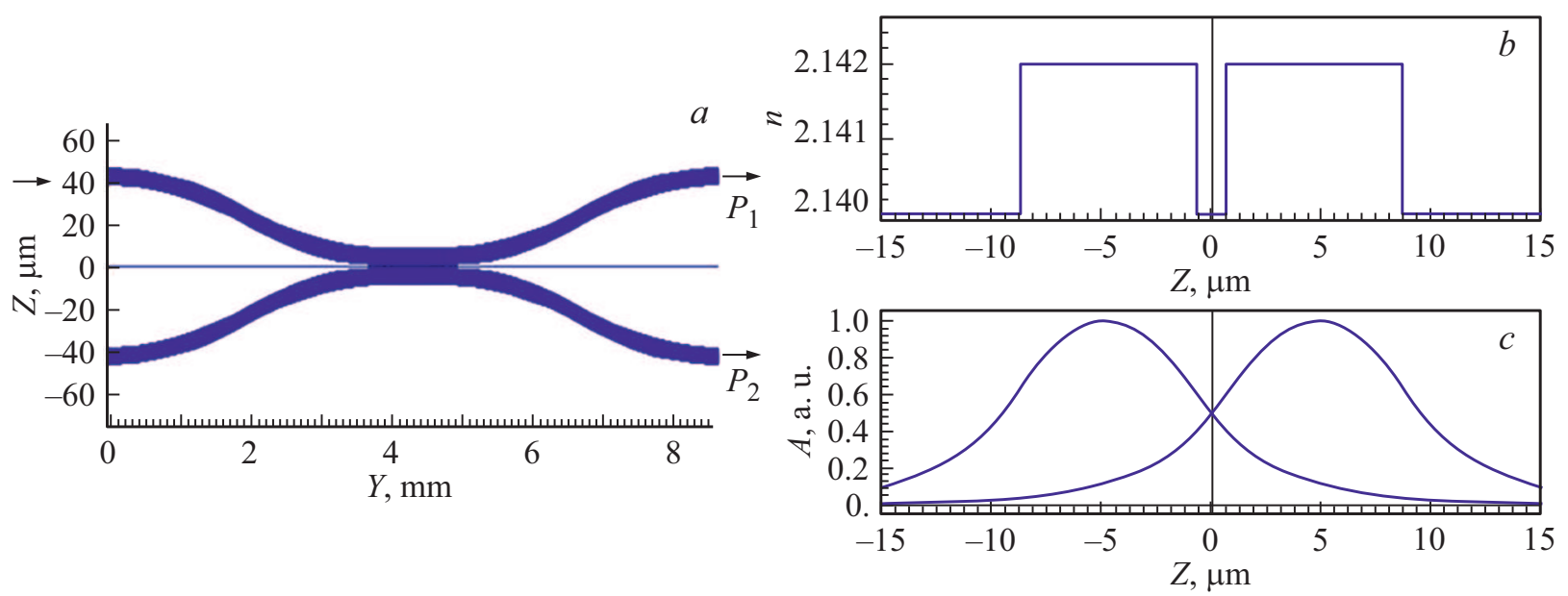

Рис. 1. Геометрия $X$-ответвителя $(a)$, профиль показателя преломления $(b)$ и распределение нормированных амплитуд оптических мод волноводов $(c)$ в центральном сечении $X$-ответвителя.
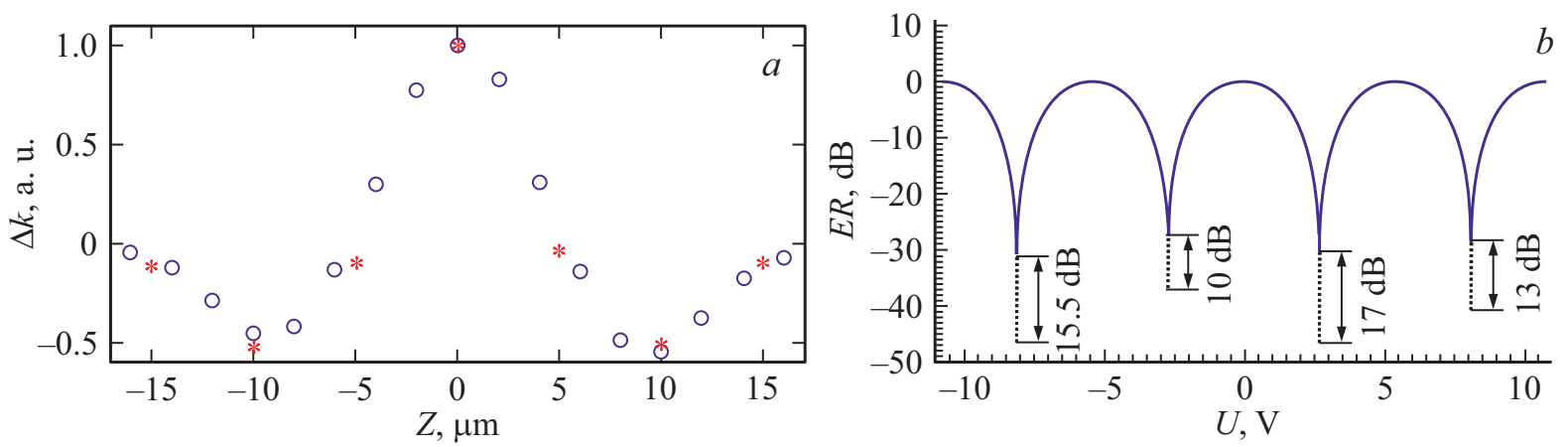

Рис. 2. $a-$ зависимость изменения коэффициента деления $X$-ответвителя от расположения области фоторефрактивной засветки (звездочками отмечены экспериментальные результаты, кружками - результаты расчета); $b$ - зависимость коэффициента контраста модулятора от напряжения на электродах до (сплошная) и после (пунктирная линия) фоторефрактивной коррекции.

нейно поляризованной параллельно поверхности кристалла [8] и чувствительной к изменению необыкновенного показателя преломления кристалла $\left(n_{e}=2.14\right)$, на длине волны $1550 \mathrm{~nm}$. Моделирование осуществлялось при различном расположении области фоторефрактивного воздействия в пределах центрального сечения $X$-ответвителя (рис. $1, b, c)$. В данном сечении происходит наиболее сильное взаимодействие соседних волноводов, и соответственно должно наблюдаться значительное влияние локального изменения показателя преломления. В ходе расчетов определялись значения оптической мощности в выходных плечах $X$-ответвителя, а затем по формуле

$$
k=\frac{P_{2}}{P_{1}+P_{2}}
$$

(где $P_{1}, P_{2}-$ мощности излучения в выходных плечах $X$-ответвителя) рассчитывалась зависимость изменения коэффициента деления от расположения области фоторефрактивной засветки. Характер зависимости приведен на рис. 2, a. Из него видно, что засветка области между волноводами приводит к уменьшению перекачки мощности между ними, а засветка с боков волноводов приводит, наоборот, к ее увеличению. Этот эффект можно объяснить деформацией оптических мод при изменении профиля показателя преломления в области засветки. Уменьшение показателя преломления в области между волноводами разводит моды дальше друг от друга, из-за этого уменьшается их перекрытие, что приводит к уменьшению связи между ними. Если же уменьшать показатель преломления с внешней стороны одного из волноводов, то это приведет к смещению его моды к центру, в сторону другого волновода, и, как следствие, к увеличению перекрытия полей мод, т.е. к увеличению связи.

Выявленный характер зависимости был подтвержден экспериментально. Для этого была собрана установка, приведенная на рис. 3. Для локальной засветки применялся зонд на основе оптического волокна SMF-28, который подводился на расстояние $5 \mu \mathrm{m}$ к поверхности подложки, при этом на поверхности подложки образовывалось пятно засветки диаметром около $10 \mu \mathrm{m}$. Для эффективного фоторефрактивного возбуждения использовалось излучение $\mathrm{He}-\mathrm{Ne}$-лазера $(\lambda=633 \mathrm{~nm}$, мощность $P=2 \mathrm{~mW})$ с временем экспозиции $t_{\text {exp }} \approx 300 \mathrm{~s}$. 


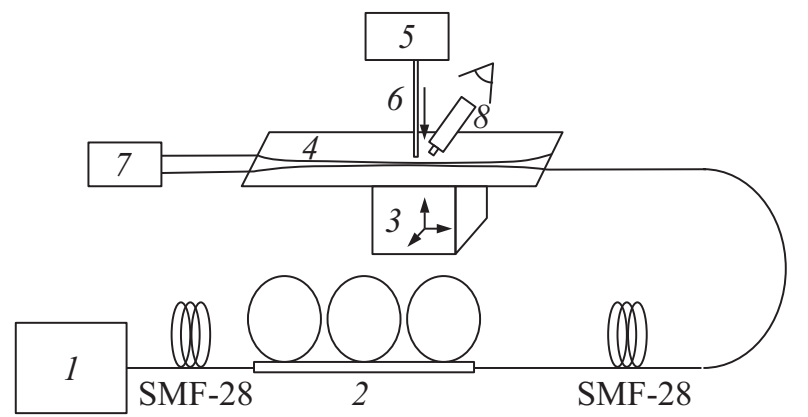

Рис. 3. Экспериментальная установка. 1 - DFB-лазер $(1550 \mathrm{~nm}), 2$ - поляризационный контроллер, 3 - трехосевая координатная подвижка, 4 - интегрально-оптический элемент, 5 - Не-Nе-лазер $(633 \mathrm{~nm}), 6$ - одномодовое оптоволокно, 7 - фотоприемник, 8 - микроскоп.

Точное позиционирование области засветки относительно топологии $X$-ответвителя производилось при помощи трехосевой микроподвижки, на которой был закреплен образец. Для регистрации изменений коэффициента деления входы и выходы $X$-ответвителя были состыкованы с оптическим волокном. Для измерений использовалось излучение одночастотного полупроводникового лазера $(\lambda=1550 \mathrm{~nm}$, мощность $P=10 \mathrm{~mW})$. Селекция ТЕ-моды обеспечивалась интегральным поляризатором на одном входе $X$-ответвителя [9]. Экспериментальные результаты фоторефрактивной подстройки коэффициента деления оптической мощности приведены вместе с результатами численного моделирования на рис. $2, a$. Максимальные изменения коэффициента деления составили величину порядка $1-2 \%$.

Важно отметить, что полученный характер зависимости дает возможность производить подстройку как в одну, так и в другую сторону от исходного значения коэффициента деления. Также важно, что результат фоторефрактивного воздействия реверсивный и может быть стерт при однородной засветке образца мощным ультрафиолетовым излучением. Этим можно пользоваться и производить фоторефрактивную подстройку по-новому в случае неудовлетворительного результата. Если же результат подстройки удовлетворительный, его можно термически зафиксировать на длительный срок [10].

Для $X$-ответвителя, входящего в состав модулятора Маха-Цендера, была сделана оценка улучшения контраста при фоторефрактивной подстройке. Предполагается, что контраст модулятора $30 \mathrm{~dB}$ определяется дисбалансом мощностей, связанным с несимметричностью одного из двух $X$-ответвителей модулятора. Значение коэффициента контраста может быть вычислено как

$$
E R=10 \lg \left(\frac{1+2 \sqrt{(1-k) k}}{1-2 \sqrt{(1-k) k}}\right)
$$

где $k$ - коэффициент деления мощности $X$-ответвителя. Изменение коэффициента деления на $2 \%$ (с 47 до 49\%) приведет к изменению коэффициента констраста на $\sim 9.5 \mathrm{~dB}$ (с 30.45 до $40 \mathrm{~dB}$ ). При необходимости большего увеличения коэффициента контраста можно производить фоторефрактивную засветку в нескольких точках $X$-ответвителя.

Предложенная методика была использована для экспериментальной демонстрации коррекции контраста интегрально-оптического модулятора Маха-Цендера. Экспериментально было продемонстрировано повышение контраста до уровня $47 \mathrm{~dB}$ (рис. 2, b). В заключение отметим, что фоторефрактивная коррекция может быть использована и для других интегрально-оптических элементов, таких как симметричный $Y$-разветвитель, делитель поляризации, модовый фильтр. Относительно простая техническая реализация метода делает его весьма перспективным для повышения характеристик уже изготовленных интегрально-оптических чипов на подложках ниобата лития.

Работа выполнена при частичной финансовой поддержке РФФИ (проект № 18-07-01174).

\section{Список литературы}

[1] Wooten E.L., Kissa K.M., Yi-Yan A., Murphy E.J., Lafaw D.A., Hallemeier P.F., Maack D., Attanasio D.V., Fritz D.J., McBrien G.J., Bossi D.E. // IEEE J. Sel. Top. Quantum Electron. 2000. V. 6. N 1. P. 69-82.

[2] Chen A., Murphy E.J. Broadband optical modulators: science, technology, and applications. Boca Raton, FL: CRC Press, 2012. P. 532.

[3] Wang X., Liu J., Li X., Li Y. // IEEE J. Quantum Electron. 2015. V. 51. N 6. P. 1-6.

[4] Brooks J., Moslehi B., Kim B. // J. Light. Technol. 1987. V. 5. N 7. P. $1014-1023$.

[5] Chen F.S. // J. Appl. Phys. 1969. V. 40. N 8. P. 3389-3396.

[6] Bazzan M., Sada C. // Appl. Phys. Rev. 2015. V. 2. N 4. P. 040603.

[7] Parfenov M., Agruzov P., Il'ichev I., Shamray A. // J. Phys.: Conf. Ser. 2016. V. 741. N 1. P. 012141.

[8] Toney J.E. Lithium niobate photonics. Norwood, MA: Artech House, 2015. $260 \mathrm{p}$.

[9] Ильичев И.В., Тогузов Н.В., Шамрай А.В. // Письма в ЖТФ. 2009. Т. 35. В. 17. С. 97-103.

[10] Grachev A.I., Chamrai A.V., Petrov M.P. // OSA TOPS. 2001. V. 62. P. 203-211. 